\title{
Rapid speciation in a newly opened postglacial marine environment, the Baltic Sea
}

\author{
Ricardo T Pereyra*1, Lena Bergström²,3, Lena Kautsky ${ }^{2}$ and \\ Kerstin Johannesson ${ }^{1}$
}

\begin{abstract}
Address: ${ }^{1}$ Department of Marine Ecology -Tjärnö, University of Gothenburg, SE 45296 Strömstad, Sweden, ${ }^{2}$ Department of Botany, Stockholm University, SE 106 91, Stockholm, Sweden and '3nstitute of Coastal Research, Swedish Board of Fisheries, SE 742 22, Öregrund, Sweden

Email: Ricardo T Pereyra* - crustaceana@gmail.com; Lena Bergström - lena.bergstrom@ fiskeriverket.se; Lena Kautsky - lena.kautsky@smf.su.se; Kerstin Johannesson - kerstin.johannesson@marecol.gu.se

* Corresponding author
\end{abstract}

Published: 3I March 2009

BMC Evolutionary Biology 2009, 9:70 doi:10.1186/147/-2/48-9-70

This article is available from: http://www.biomedcentral.com/I47/-2/48/9/70

(C) 2009 Pereyra et al; licensee BioMed Central Ltd.

This is an Open Access article distributed under the terms of the Creative Commons Attribution License (http://creativecommons.org/licenses/by/2.0), which permits unrestricted use, distribution, and reproduction in any medium, provided the original work is properly cited.
Received: 21 November 2008

Accepted: 31 March 2009

\begin{abstract}
Background: Theory predicts that speciation can be quite rapid. Previous examples comprise a wide range of organisms such as sockeye salmon, polyploid hybrid plants, fruit flies and cichlid fishes. However, few studies have shown natural examples of rapid evolution giving rise to new species in marine environments.

Results: Using microsatellite markers, we show the evolution of a new species of brown macroalga (Fucus radicans) in the Baltic Sea in the last 400 years, well after the formation of this brackish water body $\sim 8-10$ thousand years ago. Sympatric individuals of $F$. radicans and $F$. vesiculosus (bladder wrack) show significant reproductive isolation. Fucus radicans, which is endemic to the Baltic, is most closely related to Baltic Sea F. vesiculosus among north Atlantic populations, supporting the hypothesis of a recent divergence. Fucus radicans exhibits considerable clonal reproduction, probably induced by the extreme conditions of the Baltic. This reproductive mode is likely to have facilitated the rapid foundation of the new taxon.

Conclusion: This study represents an unparalleled example of rapid speciation in a species-poor open marine ecosystem and highlights the importance of increasing our understanding on the role of these habitats in species formation. This observation also challenges presumptions that rapid speciation takes place only in hybrid plants or in relatively confined geographical places such as postglacial or crater lakes, oceanic islands or rivers.
\end{abstract}

\section{Background}

Speciation is one of the most fundamental processes in evolutionary biology. It is a process in which the within population variation transforms into distinguishable groups of individuals through the evolution of intrinsic reproductive barriers [1]. The speed at which this process happens is still intriguing and controversial [2] but estimates of speciation rates generally show that $10^{5}-10^{7}$ years (yrs) are needed for new species to evolve [3]. However, theory predicts that speciation can happen more quickly -often called "contemporary" or "rapid evolution"-, particularly in new or extreme environmental conditions where selection for adaptation is strong $[2,4,5]$. Despite these theoretical expectations, the evidence of rapid speciation is primarily limited to classical evolutionary models such as cichlid fishes in discrete geographical 
spaces as a Nicaraguan crater lake [6] where competition is expected to be high and reproductive isolation is likely to occur within, or Hawaiian fauna [7] where the high number of species are more likely to drive speciation [8]. Evidence is also provided from fruit flies under laboratory conditions [9], from homoploid and polyploid hybrid plants $[10,11]$ and from anadromous sockeye salmon in which some degree of reproductive isolation evolved after 13 generations [12]. For marine species, support for rapid speciation derives from the "white" sticklebacks and although the evidence is consistent with a rapid species origin, the estimates of divergence time do not correspond with the glacial history of these systems [13]. Hence, the rapid foundation of new species in the marine environment remains to be proven.

In the marine realm, genetic divergence between populations is expected to evolve relatively slowly as recruits and propagules are readily transported by ocean currents [14]. Hitherto, time estimates for marine speciation events that agree with geological events confirm the expectations of slow speciation; for example, the reproductive isolation between sister lineages of marine shrimps was completed $>3.5$ million years ago (Mya) [15], after the rise of the Isthmus of Panama.

The Baltic Sea, today a large postglacial brackish-water basin of the NE Atlantic, hosts a low number of marine species. These species (together with a number of other now extinct ones), invaded the Baltic from the Atlantic during an earlier period of more marine conditions (4-8 thousand years ago, kya) and survived the shift 4 kya to the present day, where the low-saline environment $(<10$ practical salinity units, psu) creates an unusual marine ecosystem. One of these species, the bladder wrack Fucus vesiculosus, is widely distributed in the sub-Arctic and temperate regions of northern Atlantic, and is currently the most dominant and ecologically important perennial large brown alga in the Baltic [16]. In the Gulf of Bothnia (northern Baltic Sea), F. vesiculosus coexists with a smaller and morphologically distinct taxon, Fucus radicans [17]. Fucus radicans is smaller and has a bushy appearance in comparison to $F$. vesiculosus, and the thalli of $F$. radicans are always less wide than those of F. vesiculosus (Fig. 1). In contrast to the pan-Atlantic distribution of F. vesiculosus, F. radicans is endemic to the Baltic Sea. Previous analyses suggested that both taxa are reproductively isolated, but this conclusion was based on a single sympatric locality from the south part of the Gulf of Bothnia $[17,18]$. Subsequent studies could not, however, resolve the evolutionary relationships between $F$. radicans and F. vesiculosus using chloroplast (RuBisCO gene) [17] or mitochondrial (intergenic spacer) [19] DNA sequence markers. Therefore, the question is whether these two species correspond to previously diverged lineages that remained different after the Last Glacial Maximum 8 kya or if F. radicans

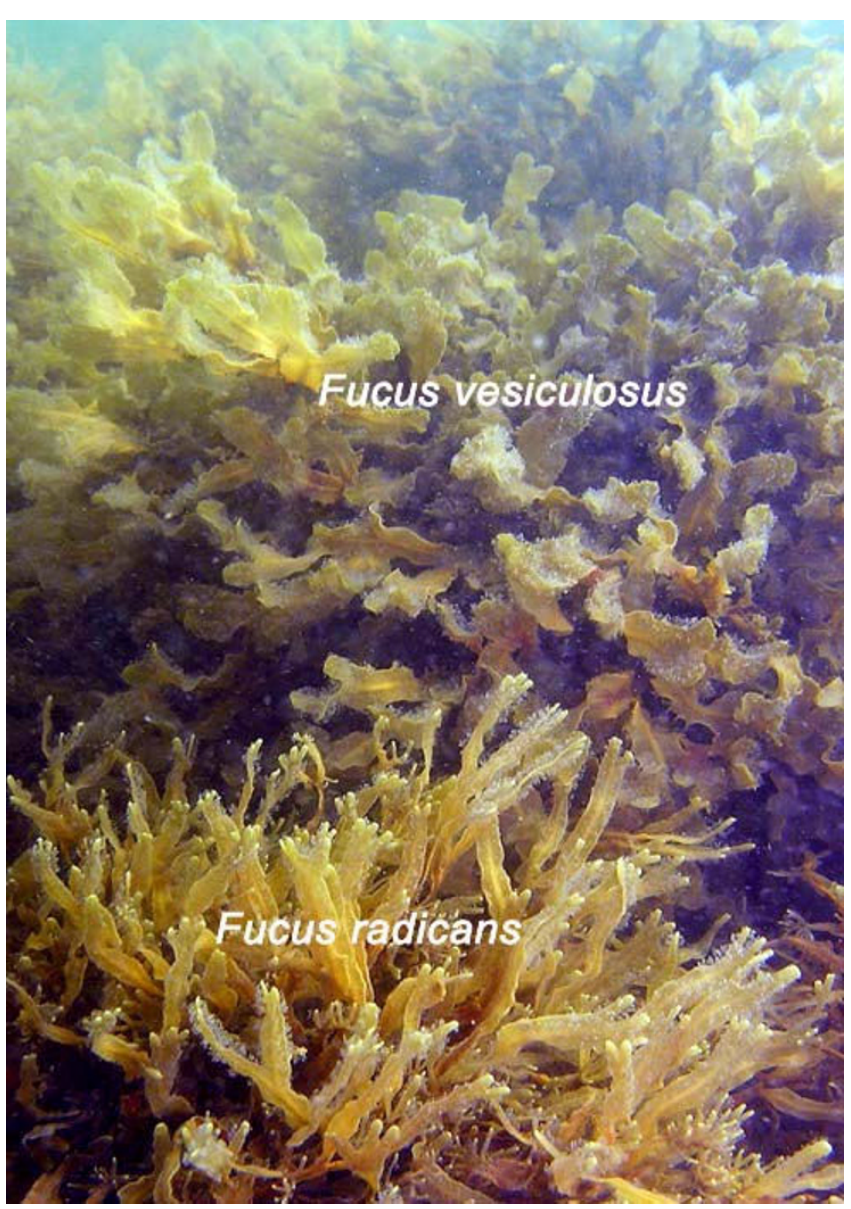

Figure I

Fucus radicans and $\boldsymbol{F}$. vesiculosus. Picture showing both Fucus species living in sympatry without any environmental discontinuity in the SW Gulf of Bothnia (northern Baltic Sea).

evolved following the last ice age, presumably inside the Baltic Sea. Here, we supplemented previous studies with four additional sympatric sites inside the Baltic and with two sites outside this region as outgroups. We also increased the set of microsatellite loci to nine. Altogether, these provided us with tools to: a) assess the reproductive isolation between F. radicans and F. vesiculosus in the supplementary populations and with the additional loci; b) determine the phylogeographic affinities of F. radicans; $\mathbf{c}$ ) estimate the time of divergence of $F$. radicans from $F$. vesiculosus to determine whether $F$. radicans originated recently, after the formation of the Baltic Sea and; d) to discern the mechanisms responsible for the reproductive isolation between F. radicans and F. vesiculosus.

\section{Results and discussion Reproductive isolation}

We assessed the reproductive isolation in four sympatric populations of $F$. radicans and $F$. vesiculosus, where both taxa are frequent in SW Gulf of Bothnia (Fig. 2A) and with 


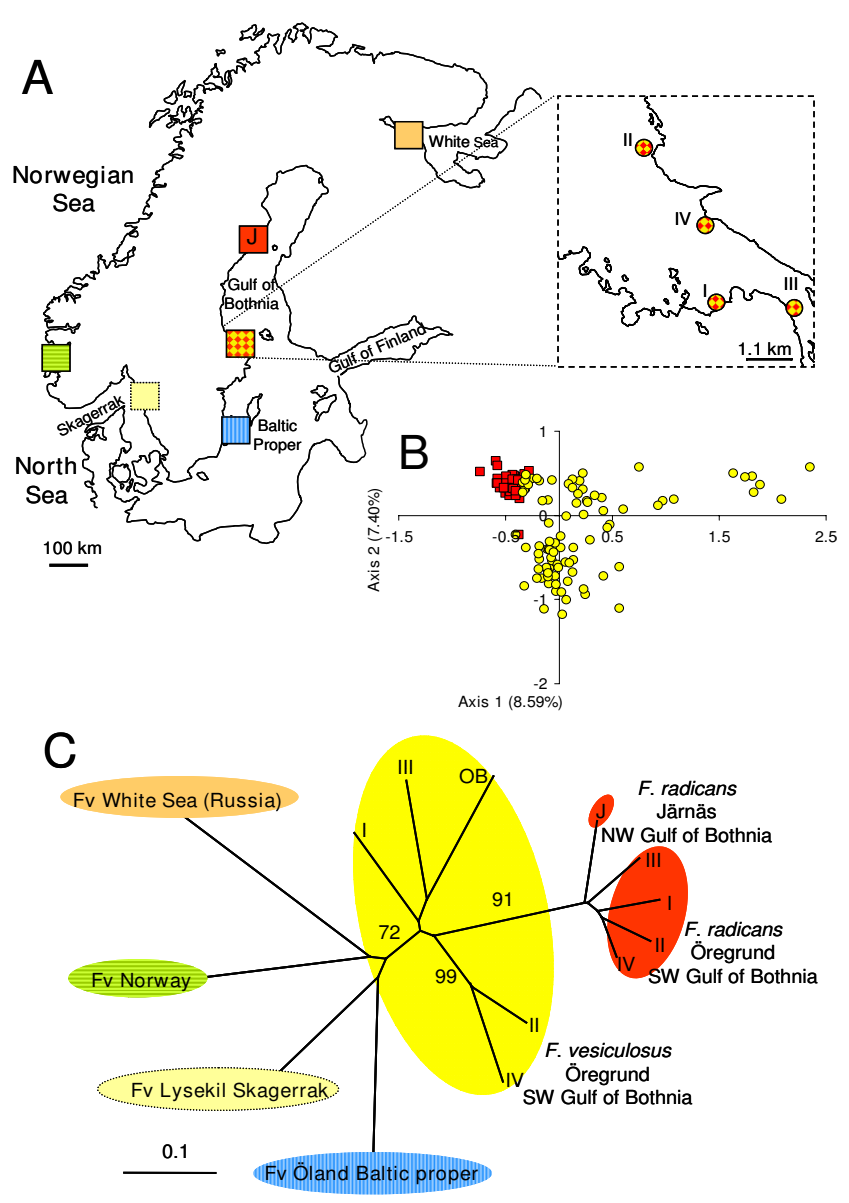

Figure 2

Sampling localities and genetic differentiation of

Fucus species. A. Map of Scandinavia showing the main sampling localities and the sampling sites in Öregrund (SW Gulf of Bothnia), where both species occur in sympatry. B. Twodimensional representation of a factorial correspondence analysis based on microsatellite genotype data. Genotypes are coloured according to species: $F$. radicans (red squares) and $F$. vesiculosus (yellow circles). $C$. Neighbour-joining microsatellite-based population tree calculated with CavalliSforza genetic distances. Fv denotes $F$. vesiculosus.

an increased set of microsatellite loci ( 9 instead of 5 from the earlier study [17]). Only individuals firmly attached to the bottom and with attached representatives of the other taxon within a distance of $<1 \mathrm{~m}$ were used in the analyses. However, the individuals representing identical genotypes (clones) were removed for all subsequent analyses (see Methods). Thus, in total we used 235 Fucus individuals with unique genotypes. All microsatellite loci were polymorphic showing 5-21 different alleles per locus and heterozygosity values $\left(H_{e}\right)$ ranging from 0.101 to 0.827 in both Fucus species (table 1). As for the reproductive isolation of $F$. radicans, considerable differences are evident from the allele frequency distributions across loci, particularly at loci Fsp1, L38, L58, and L94 (Fig. 3). At least one allele represented with high frequency in each locus in $F$. vesiculosus is not present in F. radicans, showing marked differences between species. Subsequently, we performed a factorial correspondence analysis to assess the species cohesion without accounting for any historic or demographic pattern that may underlie the taxa identities. These results showed a clear assembly among $F$. radicans individuals, while some $F$. vesiculosus individuals appeared scattered and a few more overlapping the $F$. radicans grouping (Fig. 2B). These overlapping individuals suggest that the species divergence might have occurred in the presence of gene flow, but without any demographic information this suggestion should be interpreted with caution. However, to determine whether this overlapping is due to morphological misclassification or the presence of hybrids we inferred individual ancestry using a Bayesian assignment analysis. Results from this analysis showed a clear separation between F. radicans and F. vesiculosus individuals with additional genetic variation in the latter that includes the potentially misclassified individuals. This clustering, however, had no discernable geographic pattern in $F$. vesiculosus but it separated unambiguously those $F$. vesiculosus individuals that seem to overlap with $F$. radicans from all the $F$. radicans individuals (Fig. $4, K=3$ ). It is also important to highlight the genetic cohesiveness amongst $F$. radicans across $550 \mathrm{~km}$ of coastline from Järnäs to Öregrund, providing further support of genetic isolation from $F$. vesiculosus. To further determine the extent of gene flow within and between species populations we used $F_{\mathrm{ST}}$ estimates, which are commonly used to investigate the magnitude of population differentiation. From this analysis, it is clear that the sympatric populations of $F$. radicans and $F$. vesiculosus identified by morphological criteria (frond width, midrib width and stipe width) [17] were indeed genetically isolated in the SW Gulf of Bothnia (table 2). An overall $F_{\mathrm{ST}}=0.160(P$ $=0.05$ ) among species' populations indicates limited gene flow between $F$. radicans and $F$. vesiculosus. Furthermore, all $F$. radicans populations were significantly different from those of $F$. vesiculosus and low, non-significant values characterize $F$. radicans populations, showing added evidence of reproductive isolation. Large genetic variation was also evident from these estimates among $F$. vesiculosus populations in agreement with previous results showing constrained gene flow in this species over short distances [20]. Yet, the differences between F. radicans and F. vesiculosus at all sympatric localities were greater than those observed within $F$. vesiculosus. Further results of the extent of gene flow between species comes from coalescent based pairwise estimates of migration between both species' populations and effective population sizes. The $95 \%$ highest probability distributions (HPD) of the number of migrants per generation showed asymmetric gene flow (Fig 5B-C). Migration values from F. vesiculosus to F. radicans had their highest probability near zero suggesting the absence of gene flow in this direction $\left(m 1=1.01 \times 10^{-4}-\right.$ 

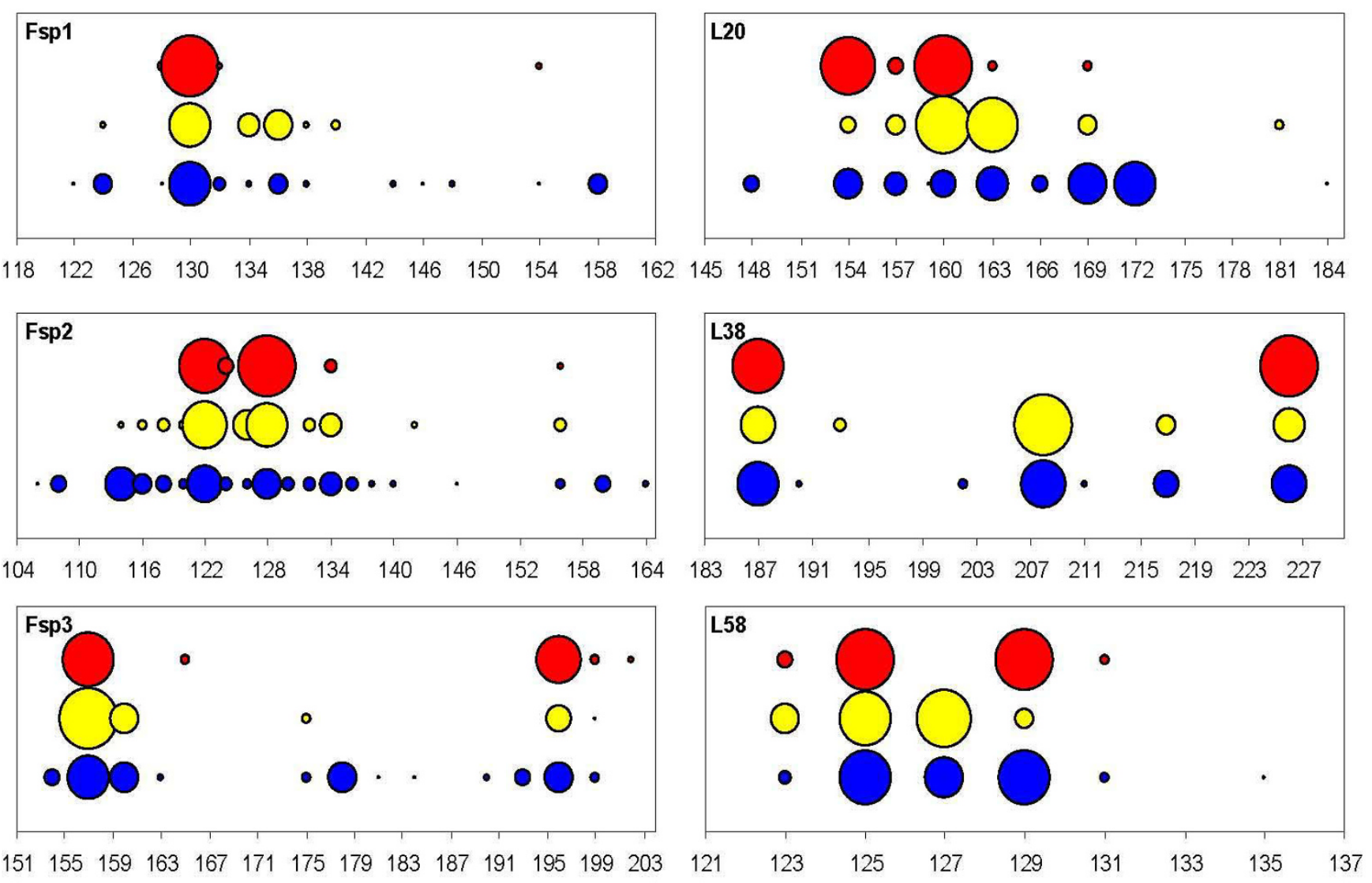

$\begin{array}{llllllllllllll}151 & 155 & 159 & 163 & 167 & 171 & 175 & 179 & 183 & 187 & 191 & 195 & 199 & 203\end{array}$
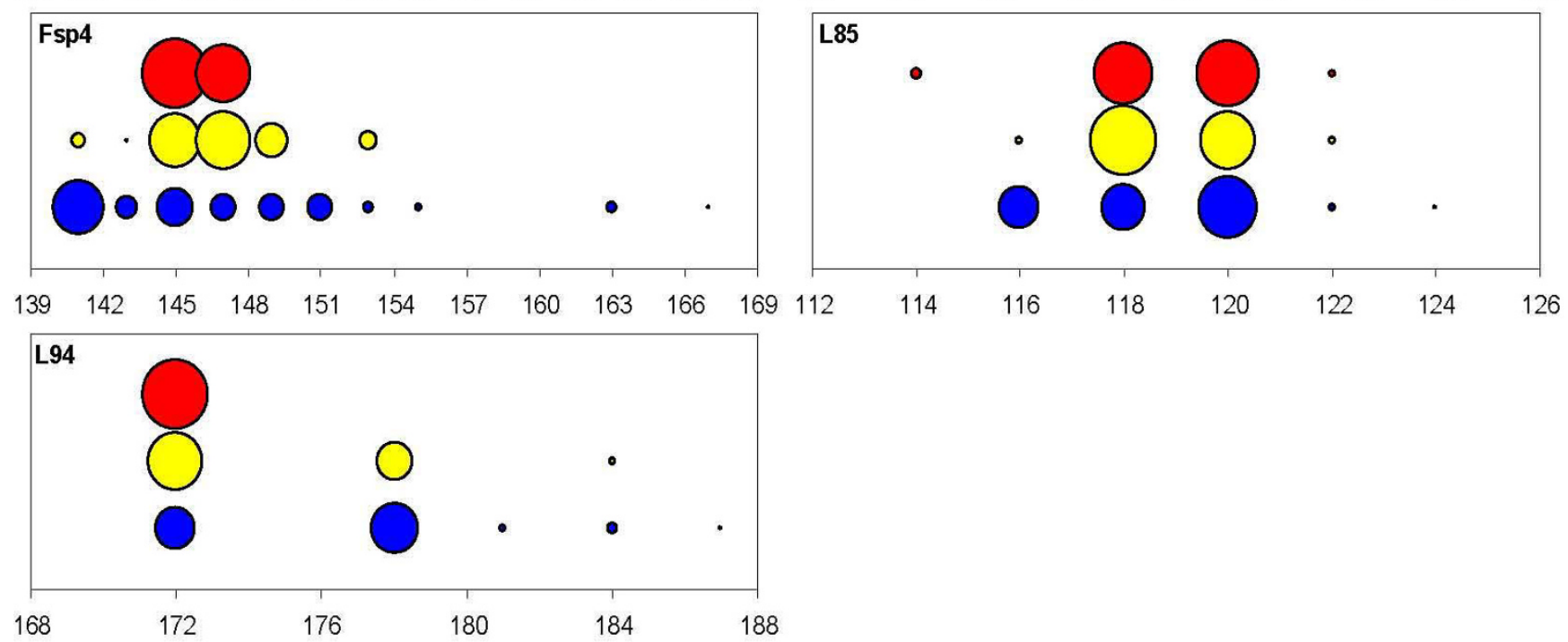

Figure 3

Allele frequency distribution of microsatellite loci. Each circle represents an allele and its frequency is proportional to the size of the corresponding circle (red: F. radicans, yellow: F. vesiculosus in Öregrund, SW Gulf of Bothnia; blue: F. vesiculosus in all other populations). 


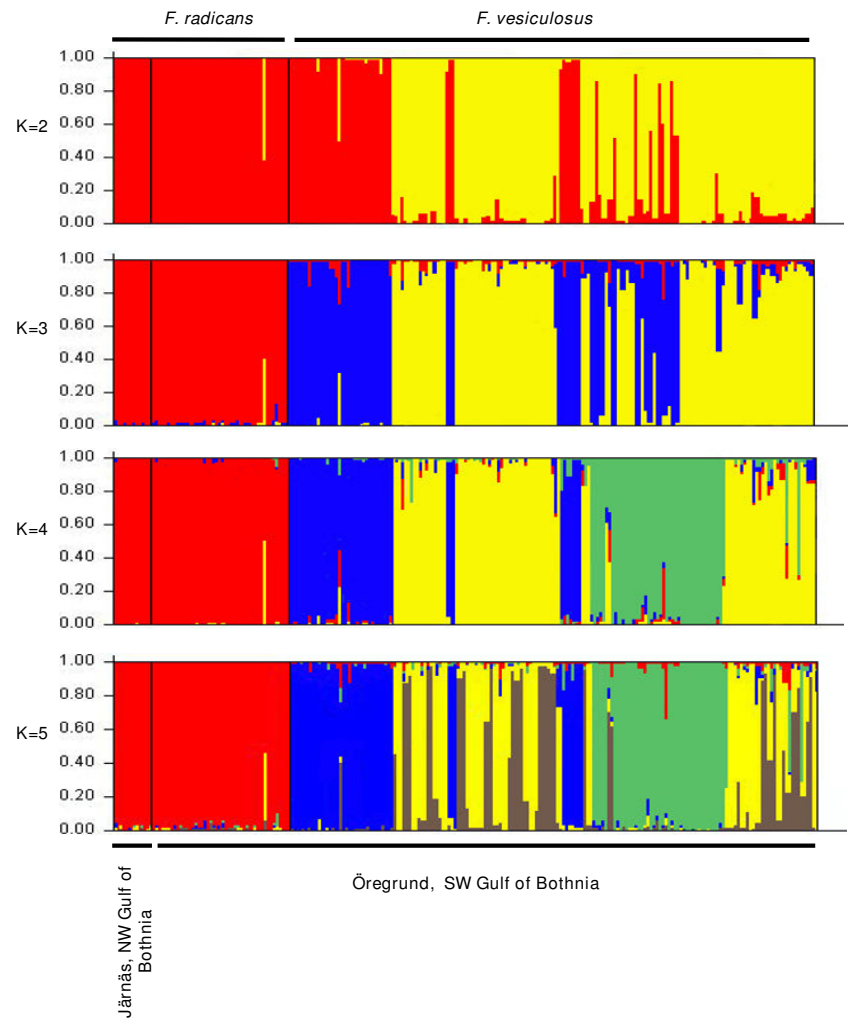

Figure 4

Histogram of Bayesian assignment tests. Analysis based on genotypes from individuals of $F$. radicans and $F$. vesiculosus exclusively from the Öregrund (SW Gulf of Bothnia) sampling sites, where both species occur in sympatry. Each bar represents an individual and its assignment probability into one of $K$ clusters. Samples are without repeated genotypes assumed to be clones. More than one color per individual indicates admixture.

$\left.2.5 \times 10^{-2}\right)$. In contrast, low but non-zero gene flow was detected from $F$. radicans to $F$. vesiculosus $\left(m 2=1.16 \times 10^{-}\right.$ $\left.3-2.7 \times 10^{-2}\right)$, supporting the suggestion of recent divergence.

\section{Phylogeographic affinities of F. radicans}

We constructed a neighbour-joining tree based on CavalliSforza genetic distances adding samples from one allopatric locality of $F$. radicans and one of $F$. vesiculosus from inside the Baltic, and three localities of $F$. vesiculosus from outside the Baltic (North Sea, Norwegian Sea and White Sea) (Fig. 2A). This analysis showed F. radicans emerging as a single monophyletic taxon derived from a F. vesiculosus lineage, but distinct from $F$. vesiculosus with high bootstrap support (Fig. 2C). The population tree indicated a close relationship between F. radicans and Gulf of Bothnia $F$. vesiculosus, suggesting that $F$. radicans recently diverged from this $F$. vesiculosus lineage. Further clustering of $F$. vesiculosus populations mainly corresponds to geographical designations and the genetic distances between them
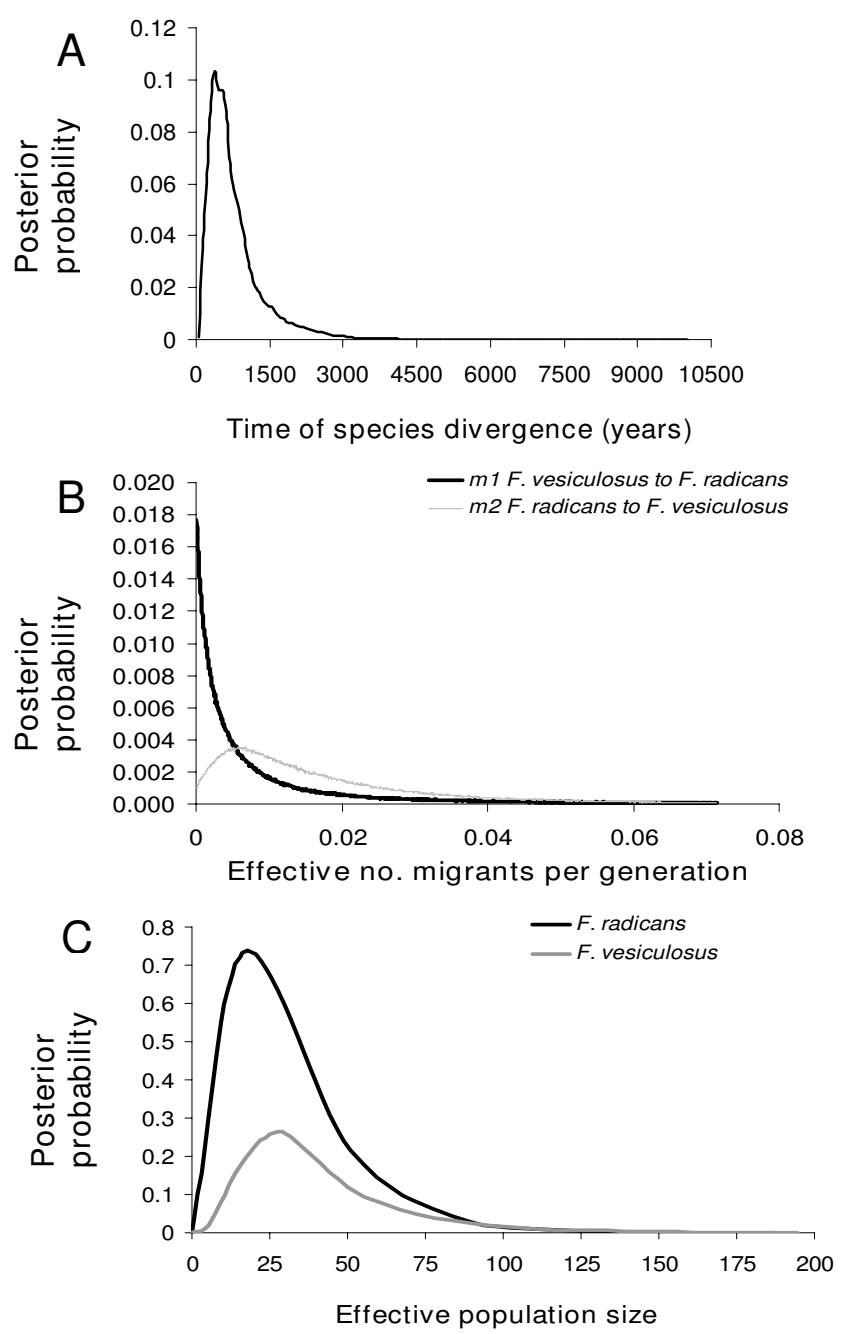

Figure 5

Approximate Bayesian posterior probability distributions for demographic parameters. A. Estimate of time since divergence $(t)$ in years. $B$. The number of effective migrants per generation from $F$. vesiculosus to $F$. radicans and vice versa. C. Estimate of effective population sizes for both species.

are in agreement with a previous study suggesting that this divergence reflects constrained gene flow even at small geographic scale [20].

\section{Time of divergence}

An alternative scenario to the hypothesis of recent speciation is that $F$. radicans may have originated outside the Baltic and entered the newly formed sea as a previously diverged lineage that remained differentiated (and became extinct outside the Baltic Sea). This scenario is weakened by our phylogeographic data: our neighbourjoining tree showed a close relationship of $F$. radicans with Baltic populations of $F$. vesiculosus that strongly supports an $F$. radicans origin within the Baltic. Yet, accurate times 
Table I: Genetic variability among microsatellite loci examined

\begin{tabular}{|c|c|c|c|c|}
\hline & $\begin{array}{l}\text { F. radicans } \\
(\mathrm{n}=39)\end{array}$ & $\begin{array}{l}\text { F. vesiculosus } \\
(\mathrm{n}=117)\end{array}$ & $\begin{array}{l}\text { F. vesiculosus other populations } \\
\qquad(\mathrm{n}=\mid 23)\end{array}$ & Total \\
\hline \multicolumn{5}{|l|}{ Fsp I } \\
\hline NA & 4 & 6 & 14 & 14 \\
\hline$H_{O}$ & 0.051 & $0.550 *$ & 0.537 & \\
\hline $\begin{array}{l}H_{\mathrm{e}} \\
\text { Fsp2 }\end{array}$ & 0.101 & 0.636 & 0.740 & \\
\hline NA & 5 & 12 & 21 & 21 \\
\hline$H_{O}$ & $0.846 *$ & $0.362 *$ & $0.306 *$ & \\
\hline $\begin{array}{l}H_{\mathrm{e}} \\
\text { Fsp3 }\end{array}$ & 0.571 & 0.780 & 0.827 & \\
\hline NA & 5 & 7 & 13 & 14 \\
\hline$H_{O}$ & 0.615 & $0.388^{*}$ & $0.499 *$ & \\
\hline $\begin{array}{l}H_{\mathrm{e}} \\
\text { Fsp4 }\end{array}$ & 0.587 & 0.522 & 0.816 & \\
\hline NA & 2 & 6 & 10 & 10 \\
\hline$H_{O}$ & 0.538 & 0.713 & 0.659 & \\
\hline $\begin{array}{l}H_{\mathrm{e}} \\
\mathbf{L} 20\end{array}$ & 0.582 & 0.708 & 0.729 & \\
\hline NA & 5 & 7 & II & I I \\
\hline$H_{O}$ & 0.615 & $0.225^{*}$ & 0.574 & \\
\hline $\begin{array}{l}H_{\mathrm{e}} \\
\mathbf{L} 38\end{array}$ & 0.567 & 0.655 & 0.774 & \\
\hline NA & 2 & 6 & 8 & 8 \\
\hline$H_{O}$ & $0.64 I$ & $0.338^{*}$ & 0.513 & \\
\hline $\begin{array}{l}H_{\mathrm{e}} \\
\mathbf{L 5 8}\end{array}$ & 0.501 & 0.651 & 0.648 & \\
\hline NA & 4 & 5 & 6 & 6 \\
\hline$H_{O}$ & $0.897^{*}$ & 0.525 & 0.597 & \\
\hline $\begin{array}{l}H_{e} \\
\text { L85 }\end{array}$ & 0.555 & 0.648 & 0.620 & \\
\hline NA & 4 & 4 & 6 & 6 \\
\hline$H_{O}$ & 0.718 & 0.575 & 0.501 & \\
\hline $\begin{array}{l}H_{\mathrm{e}} \\
\mathbf{L 9 4}\end{array}$ & 0.567 & 0.593 & 0.607 & \\
\hline NA & 1 & 3 & 5 & 5 \\
\hline$H_{O}$ & - & $0.275^{*}$ & 0.336 & \\
\hline$H_{\mathrm{e}}$ & - & 0.454 & 0.536 & \\
\hline
\end{tabular}

Sample sizes in "F. radicans" and "F. vesiculosus" only correspond to sympatric samples from Öregrund and using exclusively unique genotypes. Number of alleles (NA), observed $\left(H_{\mathrm{o}}\right)$ and expected $\left(H_{\mathrm{e}}\right)$ heterozygosities at each microsatellite locus. Significant deviations from Hardy-Weinberg equilibrium after Bonferroni correction are indicated by asterisks.

Table 2: Pairwise $\mathbf{F}_{\mathrm{ST}}$ values of population differentiation

\begin{tabular}{|c|c|c|c|c|c|c|c|c|}
\hline & $\operatorname{Fr}(\mathrm{J})$ & $\operatorname{Fr}(\mathrm{I})$ & Fr (II) & Fr (III) & $F v(I)$ & Fv (II) & Fv (III) & Fv (IV) \\
\hline $\operatorname{Fr}(\mathrm{J})$ & - & & & & & & & \\
\hline $\operatorname{Fr}(\mathrm{I})$ & 0.0189 & - & & & & & & \\
\hline $\operatorname{Fr}(\mathrm{II})$ & 0.0013 & 0.0164 & - & & & & & \\
\hline Fr (III) & 0.0019 & 0.0454 & 0.0088 & - & & & & \\
\hline Fv (I) & $0.2305^{*}$ & $0.1864^{*}$ & $0.2043 *$ & 0.1889 & - & & & \\
\hline Fv (II) & $0.1980 *$ & $0.1854 *$ & $0 .|74| *$ & $0 .|54| *$ & 0.0946 & - & & \\
\hline Fv (III) & $0.2197 *$ & $0.1901 *$ & $0.1848 *$ & 0.1780 & $0.1539 *$ & $0.1694^{*}$ & - & \\
\hline Fv (IV) & $0.2839 *$ & $0.2650 *$ & $0.2543 *$ & 0.2348 & 0.1554 & 0.1004 & 0.1650 & - \\
\hline
\end{tabular}

F-statistics were calculated among collecting sites in Öregrund (SW Gulf of Bothnia) where both Fucus species occur in sympatry. Asterisks indicate significant $P$-values after Bonferroni correction $(P \leq 0.05)$. Abbreviations indicate $F$. radicans $(F r)$ and $F$. vesiculosus ( $F v)$. Roman numbers indicate the collecting sites according to Fig. $2 \mathrm{~A}$. 

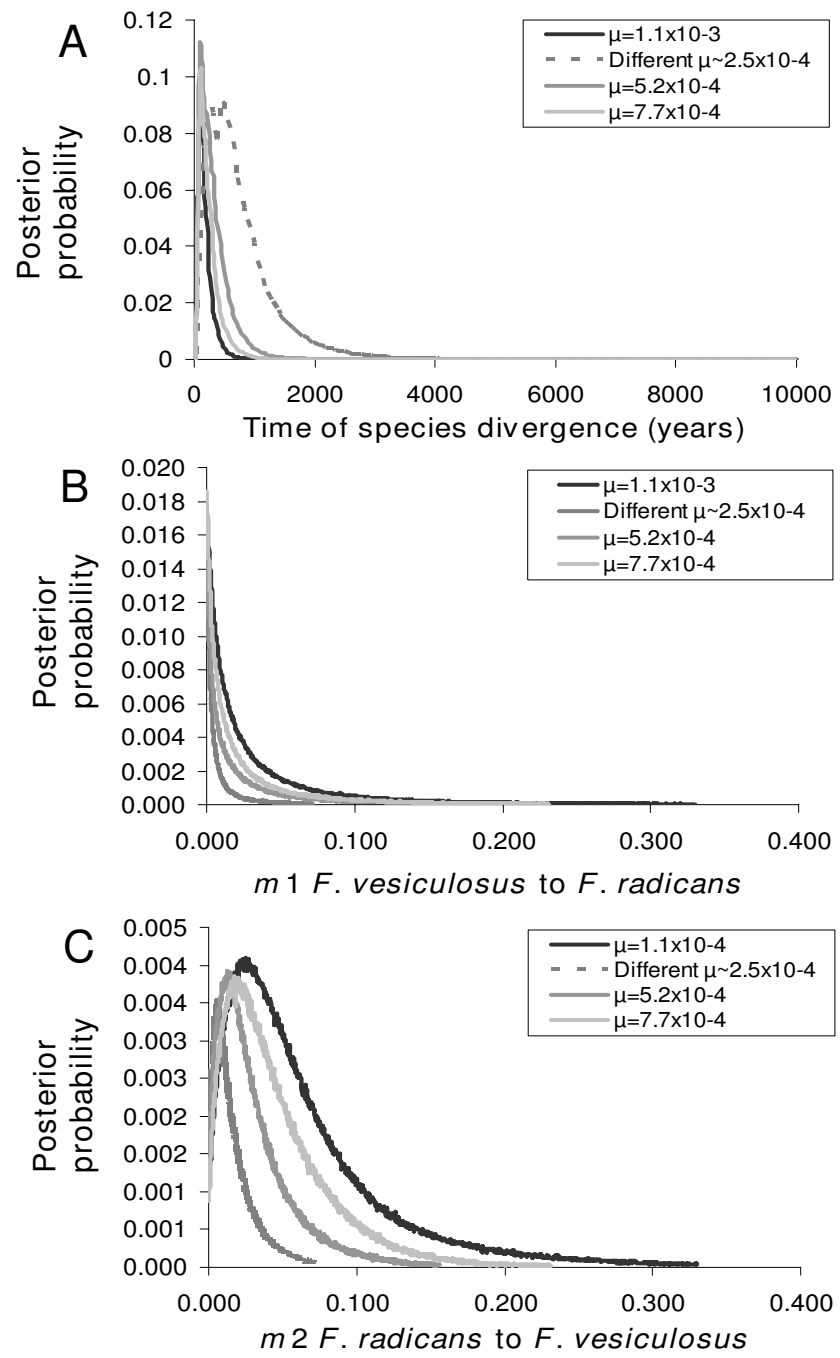

Figure 6

Approximate Bayesian posterior probability distributions for demographic parameters using different microsatellite mutation rates. A. Estimate of time since divergence $(t)$ in years. $B$. The number of effective migrants per generation from $F$. vesiculosus to $F$. radicans $(m I)$. C. The number of effective migrants per generation from $F$. radicans to $F$. vesiculosus $(\mathrm{m} 2)$.

of speciation are difficult to estimate due to the lack of variation in sequence loci. Neither nuclear or mtDNA sequences were able to resolve the phylogenetic relationships between both taxa $[17,19,21]$, further suggesting a recent origin of $F$. radicans. Consequently, we calculated a microsatellite-based estimate of time since divergence of $F$. radicans and $F$. vesiculosus using a coalescent approach. This analysis indicated that $F$. radicans and $F$. vesiculosus started to diverge from a common panmictic population sometime between 125 and 2475 yrs ago (95\%HPD; posterior distribution peak at 400 yrs ago, Fig. 5A). Hence, separation took place after the Baltic underwent the transition from marine to brackish water, less than 4 kya. The hypothesis that $F$. radicans arouse recently is further strengthened by the fact that it is endemic to the Baltic Sea.

\section{Isolating mechanisms}

We considered the mating system as a potential isolating mechanism between $F$. radicans and $F$. vesiculosus. Fucus vesiculosus has separate sexes and was until recently reported to reproduce exclusively sexually through external fertilization. Experiments show limited capacity of F. vesiculosus to reproduce in low salinities by reducing the longevity and motility of the gametes $[22,23]$, low fertilization success and egg polyspermy [22]. However, asexual reproduction $(20 \%)$ has also been reported in Baltic populations of $F$. vesiculosus [18]. Likewise, F. radicans has permanent and well established populations in all its distributional range, with separate sexes and sexual reproduction taking place the same way as in F. vesiculosus. However, it shows high extent of clonality and re-attachment experiments in both species show that detached thallus fragments of $F$. radicans have considerably higher capacity to re-attach $(80 \%)$ than those of F. vesiculosus (15\%) [18].

Populations living in marginal environments typically switch or are capable of asexual reproduction [24], and this is also true for several species in the Baltic [25]. Thus, the frequent clonal reproduction observed in $F$. radicans coupled with the low capacity of F. vesiculosus to reproduce sexual or asexually at low salinities may have facilitated the divergence between both taxa. The evolution of low-salinity tolerance might be seen as directional selection in $F$. radicans and $F$. vesiculosus. Clonality may have evolved through a single $F$. radicans individual successfully colonizing and producing a population in the hyposaline environment or through reinforcement to reduce gene flow from F. vesiculosus populations not adapted to these conditions. In either case, reproductive isolation would appear as a by-product of adaptation.

The Baltic is an ecologically marginal and geographically peripheral marine habitat due to its permanent low salinity and geographic semi-isolation from the Atlantic. The salinity gradient from the inner Baltic to the North Sea spans an order of magnitude (3-30 psu), and has caused strong local adaptation in most of the marine lineages that survived the marine/brackish transition 4 kya [25]. Directional selection is a strong promoter of speciation, even in the presence of gene flow [26-28]. More specifically, environmental stress along gradients has been highlighted as a potential source of new species [29]. Although the exact mechanism of the $F$. vesiculosus - F. radicans speciation event remains unknown, the extreme environmental stress imposed by the brackish water environment of the Baltic has clearly contributed to the formation of the new species.

\section{Conclusion}

Fucus radicans is endemic to the Baltic Sea that formed only 8-10 kya. This species diverged from $F$. vesiculosus 
and divergence time estimates suggest that they split about 400 yrs ago. These dates are consistent with the transition of the Baltic from marine to brackish water, less than 4 kya and provide an unparalleled example of rapid speciation in marine ecosystems. These closely related species also offer further opportunities to increase our understanding of the role of species-poor systems -where competition is low and gene flow is expected to be high-, of peripheral extreme environments and of mixed reproductive modes in species formation.

\section{Methods}

\section{Sample collection}

Individuals of $F$. radicans and F. vesiculosus were collected from four different areas along the Swedish coast. The area of Öregrund (SW Gulf of Bothnia) included four sites in which the distributional ranges of both species overlap and individual plants occur in sympatry (Figs. 1, 2A and 2C). The following additional sites were also included: one sampling site at Järnäs (NW Gulf of Bothnia) where only $F$. radicans is found; Öregrund $(\mathrm{OB}, F$. vesiculosus, $\mathrm{n}=$ 37, Fig. 2C); Öland ( $\mathrm{n}=43$, Baltic) and Lysekil $(\mathrm{n}=42$, Swedish west coast) where only F. vesiculosus occurs. Two further populations of $F$. vesiculosus were sampled from Norway $(n=20)$ and the White Sea $(n=18)$ for use as outgroups. Total number of unique genotypes used for the analyses is provided in table 1.

\section{Genotyping}

DNA was extracted from dried algal tissue using DNeasy Plant MiniKit and samples were genotyped at nine microsatellites developed from Fucus species [30,31]. Labelled products were poolplexed and resolved on a BeckmanCoulter automated sequencer and CeqMan 8000 software (Beckman-Coulter) was used for allele sizing.

\section{Summary statistics}

For each species, the probability of identity of genotypes was calculated to distinguish between clones and identical genotypes by chance using GIMLET http://pbil.univlyon1.fr/software/Gimlet/gimlet\%20frame1.html. The individuals representing clones were removed for all subsequent analyses. Allele variation and genetic diversity were obtained with POP100GENE http://www.montpel lier.inra.fr/URLB/pop100gene/pop100gene.html (table 1 and Fig. 3). Tests for linkage disequilibrium, Hardy-Weinberg departures and their statistical significance were performed using GENEPOP 4.0 http://kimura.univmontp2.fr/\%7Erousset/Genepop.htm.

\section{Population differentiation and Bayesian population assignment test}

First, to identify and illustrate in the factorial space the degree of similarity in allelic states between populations of both taxa from Öregrund, where they occur in sympa- try, a factorial correspondence analysis (FCA) was carried out using GENETIX 4.03 http://www.genetix.univmontp2.fr/genetix/genetix.htm (Fig. 2B). Subsequently, to examine whether sympatric populations of $F$. radicans and $F$. vesiculosus are genetically different and to measure the difference magnitudes, F-statistics were calculated using FSTAT 2.9.3 http://www2.unil.ch/popgen/soft wares/fstat.htm and significance levels were Bonferronicorrected (table 2). Then, to assess the genetic affinities between species and populations a neighbour-joining tree was constructed using Cavalli-Sforza genetic distances with 10,000 bootstrap support replicates on locus information using POPULATIONS http://bioinformatics.org/ utryphon/populations/ (Fig. 2C). Finally, to provide an alternative classification of individuals and identification of potential hybrids, a Bayesian assignment analysis was also performed using STRUCTURE 2.2 http:// pritch.bsd.uchicago.edu/software.html with a burn-in period of 50,000 and 1,000,000 iterations. The algorithm infers individual ancestry by assigning sampled individuals into a user-defined number of clusters $(\mathrm{K})$ /populations that minimize genotypic disequilibrium under the assumption of random mating. The maximum number of clusters was set to $K=5$, (Fig. 4).

\section{Estimation of demographic parameters of species divergence}

Coalescent-based estimates of time since divergence of the two species and effective number of migrants per generation were calculated using IM http://lifesci.rutgers.edu/ nheylab/HeylabSoftware.htm\#IM. Asymmetrical gene flow $(m 1 \neq m 2)$ was allowed because preliminary runs indicated that migration rates were different. Wide uninformative prior distributions were assigned based on three preliminary trial runs. Metropolis coupling was implemented using 20 chains with a 20 chain swap attempts per step and a geometric heating increment. A burn-in period of 500,000 steps was used and results were recorded every hour for $>20,000,000$ steps, so that the lowest effective sample sizes (ESS) for each parameter were 500 [32]. To test for the performance of the program, the analysis was conducted five times under identical parameterization but with different random number seeds. Given that the mutation is critical to convert the coalescent estimates to biologically informative demographic parameters, a series of analyses were conducted using different mutation rates to establish a confidence interval of coalescent estimates (Fig. 6). The upper $\left(5.2 \times 10^{-4}\right)$ and lower $\left(1.1 \times 10^{-3}\right) 95 \%$ confidence limits of mutation rate for nuclear microsatellite loci of plants [33] were used as reference. A point estimate of $7.7 \times 10^{-4}$ for microsatellite with dinucleotide repeats was also used from plants. However, since our data comprises microsatellite loci with di- and trinucleotide repeats, mutation rates for each locus used in our study were calculated indirectly using Msvar $1.3 \mathrm{http}: /$ 
www.rubic.rdg.ac.uk/ mab/stuff/. These mutation rates $\left(2.5 \times 10^{-4}\right.$ geometric mean $)$ produced the most conservative coalescent estimates from IM and therefore are the ones presented in the main results (Fig. 5). Finally, a generation time of 6 yrs [34] was assumed to convert the coalescent estimates to demographic parameters.

\section{Authors' contributions}

RTP, LB, LK and KJ designed research. LB and LK conducted field collection, RTP performed molecular and statistical analysis and drafted manuscript, KJ participated in drafting the manuscript. LB and LK revised critically the manuscript. All authors read and approved the final manuscript.

\section{Acknowledgements}

We thank A. Tatarenkov for advice during early stages of work and for comments on the manuscript, to $B$. Jönsson for assistance in the laboratory and to J. Havenhand, C. André, R. K. Butlin and B. Emerson for valuable comments. This work was financially supported by the Swedish Research Councils (VR and Formas) partly through the BaltGene research program and the Linnaeus initiative 'Adaptation to changing marine environments (ACME)'.

\section{References}

I. Noor MAF, Feder JL: Speciation genetics: evolving approaches. Nat Rev Genet 2006, 7:85I-86I.

2. Hendry AP, Nosil P, Rieseberg LH: The speed of ecological speciation. Funct Ecol 2007, $21: 455-464$.

3. Coyne JA, Orr HA: Speciation Sunderland: Sinauer; 2004.

4. Gavrilets S: Models of speciation: what have we learned in $\mathbf{4 0}$ years? Evolution 2003, 57:2197-2215.

5. Johannesson K, Johannesson B, Lundgren U: Strong natural selection causes microscale allozyme variation in a marine snail. Proc Natl Acad Sci USA 1995, 92:2602-2606.

6. Barluenga M, Stölting KN, Salzburger W, Muschick M, Meyer A: Sympatric speciation in Nicaraguan crater lake cichlid fish. Nature 2006, 439:719-723.

7. Mendelson TC, Shaw KL: Rapid speciation in an arthropod. Nature 2005, 433:375-376.

8. Emerson BC, Kolm N: Species diversity can drive speciation. Nature 2005, 434:1015-1017.

9. Higgie M, Chenoweth $\mathrm{S}$, Blows MW: Natural selection and the reinforcement of mate recognition. Science 2000, 290:5। 9-52।.

10. Ungerer MC, Baird SJE, Pan J, Rieseberg LH: Rapid hybrid speciation in wild sunflowers. Proc Natl Acad Sci USA 1998, 95: I 1757-I I762.

11. Kovarik A, Pires JC, Leitch AR, Lim KY, Sherwood AM, Matyasek R, Rocca J, Soltis DE, Soltis PS: Rapid concerted evolution of nuclear ribosomal DNA in two Tragopogon allopolyploids of recent and recurrent origin. Genetics 2005, 169:931-944.

12. Hendry AP, Wenburg JK, Bentzen P, Volk EC, Quinn TP: Rapid evolution of reproductive isolation in the wild: Evidence from introduced salmon. Science 2000, 290:516-518.

13. McKinnon JS, Rundle HD: Speciation in nature: the threespine stickleback model systems. Trends Ecol Evol 2002, 17:480-488

14. Palumbi SR: Genetic divergence, reproductive isolation and marine speciation. Annu Rev Ecol Syst 1994, 25:547-572.

15. Knowlton N, Weigt LA, Solorzano LA, Mills DEK, Bermingham E: Divergence in proteins, mitochondrial DNA, and reproductive compatibility across the Isthmus of Panama. Science 1993, 260:1629-1632.

16. Kalvas A, Kautsky L: Geographic variation in Fucus vesiculosus morphology in the Baltic and North Seas. Eur J Phycol 1993, 28:85-9l.

17. Bergström L, Tatarenkov A, Johannesson K, Jönsson RB, Kautsky L: Genetic and morphological identification of Fucus radicans sp. nov. (Fucales, Phaeophyceae). J Phycol 2005, 41:900-905.
18. Tatarenkov A, Bergström L, Jönsson RB, Serrão EA, Kautsky L, Johannesson $\mathrm{K}$ : Intriguing asexual life in marginal populations of the brown seaweeds, Fucus vesiculosus. Mol Ecol 2005, 14:647-65I.

19. Coyer JA, Hoarau G, Oudot-Le Secq MP, Stam WT, Olsen JL: A mtDNA-based phylogeny of the brown algal genus Fucus (Heterokontophyta; Phaeophyta). Mol Phylogenet Evol 2006, 39:209-222.

20. Tatarenkov A, Jönsson RB, Kautsky L, Johannesson K: Genetic structure in populations of Fucus vesiculosus (Phaeophyceae) over spatial scales from $10 \mathbf{~ m}$ to $800 \mathbf{~ k m}$. J Phycol 2007, 43:675-685.

21. Serrão EA, Alice LA, Brawley SH: Evolution of the Fucaceae (Phaeophyceae) inferred from nrDNA-ITS. J Phycol 1999, 35:382-394.

22. Serrão EA, Kautsky L, Brawley SH: Distributional success of the marine seaweed Fucus vesiculosus $L$. in the brackish Baltic Sea correlates with osmotic capabilities of Baltic gametes. Oecologia 1996, 107:1-12

23. Pearson G, Kautsky L, Serrão E: Recent evolution in Baltic Fucus vesiculosus: reduced tolerance to emersion stresses compared to intertidal (North Sea) populations. Mar Ecol Prog Ser 2000, 202:67-79.

24. Eckert CG: The loss of sex in clonal plants. Evol Ecol 2002, I 5:50I-520.

25. Johannesson $\mathrm{K}$, André C: Life on the margin - genetic isolation and loss of variation in a peripheral marine ecosystem. Mol Ecol 2006, 15:2013-2030.

26. Rieseberg LH, Widmer A, Arntz MA, Burke JM: Directional selection is the primary cause of phenotypic diversification. Proc Natl Acad Sci USA 2002, 99: I 2242-I 2245.

27. Korol A, Rashkovetsky E, lliadi K, Nevo E: Drosophila flies in "Evolution Canyon" as a model for incipient sympatric speciation. Proc Natl Acad Sci USA 2006, 103:18184-18189.

28. Doebeli M, Dieckmann U: Speciation along environmental gradients. Nature 2003, 421:259-264.

29. Lexer C, Fay MF: Adaptation to environmental stress: a rare or frequent driver of speciation? J Evol Biol 2005, I 8:893-900.

30. Engel CR, Brawley SH, Edwards KJ, Serrão E: Isolation and crossspecies amplification of microsatellite loci from the fucoid seaweeds Fucus vesiculosus, F. serratus and Ascophyllum nodosum (Heterokontophyta, Fucaceae). Mol Ecol Notes 2003, 3:180-182.

31. Perrin C, Daguin C, Vliet M Van De, Engel CR, Pearson GA, Serrão $E A$ : Implications of mating system for genetic diversity of sister algal species: Fucus spiralis and Fucus vesiculosus (Heterokontophyta, Phaeophyceae). Eur J Phycol 2007, 42:219-230.

32. Hey J, Nielsen R: Multilocus methods for estimating population sizes, migration rates and divergence time, with applications to the divergence of Drosophila pseudoobscura and D. persimilis. Genetics 2004, 167:747-760.

33. Vigouroux $Y$, Jaqueth JS, Matsuoka $Y$, Smith OS, Beavis WD, Smith JSC, Doebley J: Rate and pattern of mutation at microsatellite loci in maize. Mol Biol Evol 2002, I 9(8): I25I-1260.

34. Malm T, Kautsky L: Differences in life-history characteristics are consistent with the vertical distribution pattern of Fucus serratus and Fucus vesiculosus (Fucales, Phaeophyceae) in the central Baltic Sea. J Phycol 2003, 39:880-887.

Publish with Biomed Central and every scientist can read your work free of charge

"BioMed Central will be the most significant development for disseminating the results of biomedical research in our lifetime. "

Sir Paul Nurse, Cancer Research UK

Your research papers will be:

- available free of charge to the entire biomedical community

- peer reviewed and published immediately upon acceptance

- cited in PubMed and archived on PubMed Central

- yours - you keep the copyright
BioMedcentral 